\title{
Horizontalidade e verticalidade: os modelos de improvisação de Pixinguinha e K-Ximbinho no choro brasileiro
}

\author{
Paula Veneziano Valente (USP, São Paulo, SP). \\ paulavalente@uol.com.br
}

\begin{abstract}
Sumário: Análise sobre os procedimentos de improvisação utilizados por Pixinguinha em 1 × 0 (1947) e por K-Ximbinho em Velhos Companheiros (1981). Uma comparação das diferenças e semelhanças entre suas abordagens mostra uma preferência pelos modelos estilísticos vertical ou horizontal.

Palavras-chave: K-Ximbinho; Pixinguinha; choro; música popular brasileira; improvisação; análise musical.

\section{Horizontal and vertical structures: Pixinguinha and K-Ximbinho's models of improvisation in the Brazilian Music}

Abstract: Analysis of the improvisation procedures of Brazilian instrumentalists Pixinguinha in 1 x 0 (One to zero; 1947) and K-Ximbinho in Velhos Companheiros (Old pals; 1981). A comparison of differences and similarities in their approaches reveals a preference for horizontal or vertical stylistic models.

Keywords: K-Ximbinho; Pixinguinha; Brazilian choro; popular music; improvisation; music analysis.

\section{1 - Introdução}

0 improviso é um procedimento comum a vários estilos e épocas, possui grande importância dentro da criação musical brasileira, e ainda é pouco considerado pela musicologia nacional. Por serem relativamente recentes os estudos nesta área, existem poucos trabalhos referentes a ele. Grande parte do material didático que temos disponivel para o estudo da improvisação se refere à música americana, mais especificamente ao jazz, sendo raros os livros dedicados à música brasileira. 0 mercado norteamericano de livros didáticos que se volta para a improvisação é vasto, provavelmente este deva ser um dos motivos da grande influência da improvisação jazzística dentro da música brasileira. Tendo em vista essa insuficiência de pesquisas e materiais de estudo, aqueles que queiram se aprimorar na linguagem do choro e na improvisação, voltam-se necessariamente aos discos ou aos próprios músicos para construir seu aprendizado. Nesse sentido, a observação das gravações é determinante, pois nelas podemos perceber aspectos como articulação, dinâmica, inflexão, variações de timbre e muitos outros efeitos instrumentais.

Destacamos neste trabalho, dois importantes improvisadores da música popular brasileira: Pixinguinha e KXimbinho. Além de improvisadores, eles também foram intérpretes, compositores e arranjadores. No entanto, será tema da nossa pesquisa somente o aspecto referente à improvisação dentro de suas obras, e por meio de seus exemplos musicais investigaremos os principais caminhos e preferências de cada um deles. A escolha dos nomes $\mathrm{Pi}$ xinguinha e K-Ximbinho foi motivada pelo fato de acreditarmos que eles representam dois modelos distintos de abordagem de improvisação.

Pixinguinha nasceu no Rio de Janeiro em 1897, onde viveu toda sua vida, falecendo em 1972. K-Ximbinho, 
nasceu em 1917 em Natal/RN, e também passou grande parte da vida no Rio de Janeiro, falecendo em 1981. A diversidade de suas concepções e de suas influências musicais é fundamental para a nossa pesquisa, uma vez que transparecem em seus improvisos, e é por meio deles que conseguiremos ilustrar diferentes procedimentos dentro de suas criações.

Em relação às influências observadas em cada um deles, notamos que para músicos populares, como no caso de Pixinguinha e K-Ximbinho, que circulavam por gêneros, estilos e performances variadas, sobreviver dentro do mercado de trabalho significava se adaptar aos gostos e modas do público e da época. Tanto Pixinguinha quanto K-Ximbinho sempre se ajustaram ao mercado, e compunham além de choros, outros estilos. Essa flexibilidade sempre fez parte da produção dos músicos brasileiros, e a assimilação das novidades estrangeiras muitas vezes se combinou às tendências musicais brasileiras.

Pixinguinha foi considerado o primeiro grande improvisador no choro e, segundo CABRAL (1978, p.20) "soube reunir uma série de elementos que andavam dispersos nas primeiras décadas do choro". K-Ximbinho pode ser considerado um exemplo da continuidade dessa prática criativa dentro da música brasileira, mesmo com uma obra não tão numerosa quanto à de Pixinguinha, e também pelo fato de ser pouco estudado dentro das pesquisas acadêmicas até o presente momento'.

Enquanto a obra de Pixinguinha já foi tema estudado, a de K- Ximbinho recebeu pouca atenção. Apesar de ter sido um compositor e instrumentista conceituado dentro da música brasileira, deparamo-nos com dificuldades em encontrar materiais sobre ele, tanto escritos quanto sonoros. A maioria de seus discos foi gravada junto à Orquestra Tabajara, de Severino Araújo, na qual atuou em grande parte de sua vida. Além dos discos com a Orquestra, gravou com outras formações menores ou também acompanhando importantes cantores de sua época. As gravações de KXimbinho estão dispersas e segundo nossas pesquisas, seu último trabalho pode ser encontrado em CD.

Durante a criação de um improviso percebemos dois caminhos básicos: um que se revela mais preocupado com a harmonia e outro com a melodia. Essas duas linhas coexistem no mesmo discurso, mas notamos a predominância de uma delas em relação à outra, dependendo de cada intérprete. Com as análises dos compositores escolhidos queremos exemplificar estes caminhos, demonstrando as diferenças e semelhanças e traçando um modelo predominante em cada um deles.

Para esse artigo, analisaremos apenas um trecho de improviso de cada autor: de Pixinguinha, o do choro $1 \times 0$ (de 1947); e de K- Ximbinho, Velhos Companheiros (de 1981). Como referências de repertório para a escolha dos improvisos selecionamos dois choros. De Pixinguinha, um choro gravado em 1947, com o flautista Benedito Lacer- da, que faz parte de uma importante fase de sua carreira, quando passou a tocar ao saxofone seus famosos "contracantos", enquanto a flauta de Benedito executava a melodia. Com a mudança de instrumento para o saxofone, os improvisos de Pixinguinha, que antes eram feitos à flauta como variações melódicas ou pequenas alterações rítmicas da voz principal, passaram a ter uma função mais subordinada à harmonia, ou seja, de acompanhamento desta voz principal. De K-Ximbinho, escolhemos uma parte de um choro gravado no disco Saudades de um clarinete, lançado em 1981. Neste disco, todas as faixas são de sua autoria, bem como os arranjos e regências, e entendemos que nesta fase seu estilo de improvisação já se encontrava consolidado e amadurecido.

Nossa principal fonte de estudo para o presente trabalho se constitui nas gravações, que serão transcritas e posteriormente analisadas. Em muitos casos, a transcrição dos solos não é suficiente para a compreensão ampla da obra, sendo necessário a audição da própria gravação, que nos possibilite ouvir as sonoridades específicas do instrumentista, suas inflexões, o tipo de interpretação que sugeriu e em que contexto se deu o improviso. Apesar de não ser o ideal para a análise de improvisos, esta será uma das fontes que utilizaremos, juntamente com as gravações.

Vale lembrar que o objetivo do pesquisador em música é tentar achar o sentido dentro da obra, que vai além das simples notações, partituras e o que elas podem revelar, percebendo as várias partes que compõem a estrutura total, identificando pontos de reflexão, a fim de encontrar o método mais eficiente de análise em cada caso específico.

Acreditamos que a solução para a análise de um improviso seja primeiramente sua transcrição a partir de uma gravação (mesmo sabendo que dificilmente conseguiremos obter uma descrição fiel do momento), e posteriormente, para complementação das análises, examinar as próprias gravações que transcrevemos a fim de observar fatores como: inflexões de frases, variação timbrística, articulações etc. Em música popular, e mais ainda na música improvisada, o performer, ou o músico tem muita liberdade em relação à partitura. Segundo NAPOLITANO (2002), tanto a estrutura quanto a performance são igualmente importantes, mas uma não deve ser reduzida à outra.

Nossa sugestão de análise restringe-se à improvisação dentro de um gênero definido, o choro; dentro de um território específico, que supõe suas delimitações e regras, citaremos Derek BAILEY (1993) que, na introdução de seu livro, Improvisation - its nature and practice in music, caracteriza as duas principais formas de improvisação - a idiomática e a não idiomática:

Idiomatic improvisation, much the most widely used, is mainly concerned with the expression of an idiom - such as jazz, flamenco or baroque - and takes its identity and motivation from that idiom. Non idiomatic improvisation has other concerns and is most usually found in so-called 'free' improvisation and, while it can be highly stylised, is not usually tied to representing an idiomatic identity ${ }^{2}$ 
Nossa pesquisa se refere à improvisação idiomática, ou seja, dentro de um idioma definido. Para auxiliar-nos nas análises iremos examinar os conceitos citados pelo autor George Russell em seu livro The Lydian Cromatic Concept of Tonal Organization for Improvisation de improvisação vertical - que prioriza a harmonia - e horizontal - que enfatiza a melodia.

Nossas análises têm como objetivo principal a caracterização de dois caminhos que são tomados no decorrer das improvisações e a sua demonstração através dos dois compositores destacados. Denominaremos estes caminhos de vertical e horizontal, e iremos examiná-los a seguir.

\section{2- Improvisação horizontal e vertical}

Para nos auxiliar na questão da análise de improvisações dentro do choro brasileiro, utilizaremos a obra de RUSSELL (2001) citada acima, em que o autor observa dois caminhos básicos dentro da improvisação que chamamos de "idiomática". Segundo Russell, uma música pode ser comparada metaforicamente a uma viagem através de um rio, e no caso da improvisação o músico tem a possibilidade de fazer esta viagem de várias maneiras. Os dois principais modos desta "navegação" são denominados como o modo ou abordagem vertical e o outro que é chamado de horizontal.

0 músico que navega por este rio pelo modo que chamamos vertical faz paradas em cada acorde, ou seja, constrói uma improvisação através da escala relativa a cada acorde. Uma improvisação neste nível, ou seja, vertical requer que o músico projete a identidade harmônica de cada acorde com a melodia, definindo os tipos de acorde na medida em que eles aparecem dentro da música. Para esta definição nota-se inicialmente uma construção baseada principalmente em terças e fundamentais dos acordes, e posteriormente, através da experimentação, outras notas além das estruturais do acorde também podem ser incorporadas, o que leva aos acordes extendidos ou alterados. Por exemplo: em um acorde de $\mathrm{C} 7$ pode-se adicionar um $\mathrm{Db}$ ou um $\mathrm{Gb}$, assim este acorde se transforma em C7/ b5/b9 (acorde dominante com a quinta diminuta e a nona menor).

Criar uma melodia que se encaixe em cada acorde dentro da respectiva progressão é o principal objetivo deste nível "vertical". 0 improvisador vertical sugere o tipo de acorde através da melodia do seu improviso. Na gravitação ver- tical a melodia é indicada pelo acorde, ela é concentrada em cada acorde da progressão.

0 outro modo de navegação por este rio é chamado de horizontal. Nesta abordagem, a melodia é construída não com paradas e definições sobre cada acorde, e sim baseada em uma escala relacionada a mais de um acorde, ou seja, ao centro tonal daquela progressão. 0 músico não precisa necessariamente definir cada acorde identificando-os um a um, mas utiliza escalas comuns a mais de um acorde. Este tipo de abordagem não realiza paradas como a vertical, em cada acorde e sim nos centros tonais.

Quando encontramos uma única nota sustentada em mais de uma acorde, ou uma única escala utilizada através de vários compassos, podemos dizer que a melodia está baseada numa abordagem horizontal.

Notamos em cada improvisador uma tendência ou preferência por um desses tipos de abordagem, mas ambos os modos caminham lado a lado e durante o improviso observamos, nem sempre muito claramente, as passagens de um modo ao outro.

Segundo BERTON (2005), baseado nos conceitos de Russell, define uma abordagem horizontal quando, por exemplo: dentro de uma cadência típica da música popular, Dm - G7 - C7M (ii,- V - I), o improvisador utiliza como material fonte a escala de Dó Maior sobre os 3 acordes, gravitando em um só centro. Dentro desta abordagem utilizam-se mais padrões escalares. No Ex.1 podemos ver claramente a aplicação de uma escala blues ${ }^{3}$ em "Sol", enquanto a progressão harmônica caminha, independentemente desta, porém, gravitando no mesmo centro "Sol".

Seguindo o raciocínio de Russell, através da dissertação de Berton, uma abordagem vertical seria quando o improvisador, dentro desta mesma cadência, utiliza três centros de gravitação, correspondentes às três fundamentais de acordes envolvidas. Em Dm7, ele pensa no segundo modo de Do (dórico), no G7 pensa no quinto modo de Do (mixolídio), e em C7M no primeiro modo de Do (jônico). Dentro desta abordagem usam-se mais arpejos (Ex.2).

Aplicando os conceitos de horizontalidade e verticalidade examinados acima, podemos notar a preponderância de um destes aspectos dentro de cada compositor estudado. Através deles pretendemos esclarecê-los e delinear tendências da improvisação dentro do choro brasileiro.

Escala de G Blues

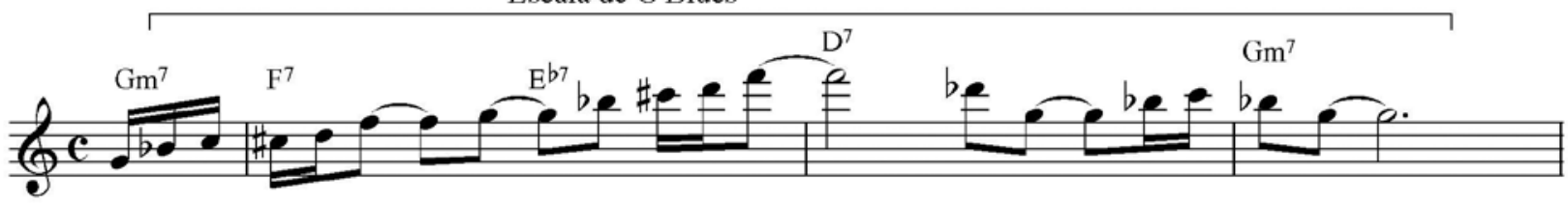

Ex.1 - Song of my father (Joe Henderson): exemplo de abordagem horizontal ${ }^{4}$ 


\section{3- 0 desenho harmônico de Pixinguinha}

Nossa análise fundamenta-se na fase em que Pixinguinha definiu sua maneira de improvisar, isto é, executar ao saxofone suas linhas de contracanto ${ }^{6}$. Nela, notaremos sua originalidade e as razões pelas quais é considerado um estruturador da linguagem do choro ao transferir o tipo de improvisação característica dos instrumentos acompanhadores (harmônicos) para 0 instrumento solista (melódico). Pixinguinha criava essas linhas paralelamente aos solos da flauta, mas quando ouvimos suas gravações podemos observar que não eram totalmente improvisadas. Em gravações da mesma música, ouvimos frases bem parecidas - o que nos faz concluir que em sua mente existia um "caminho" traçado pela harmonia da música, e no momento da execução poderia ou não repetir certos elementos sempre criando linhas que revelavam claramente a harmonia. A concepção destas linhas é similar às do baixo (ou da "baixaria" como é denominado no choro) e podemos ouvi-las desde as primeiras gravações.

Para a análise dos choros de Pixinguinha, utilizaremos como ferramenta a relação entre o acorde dado e as notas da melodia criada sobre este mesmo acorde. Esse modo de análise nos parece mais adequado para demonstrar se seus improvisos estão fundamentados principalmente em estruturas verticais (baseadas em notas de acorde) ou horizontais (baseadas em escalas referentes às sequências harmônicas).

Nota-se no Ex.3, que sem se descuidar da condução melódica, Pixinguinha descreve a harmonia praticamente em todo o improviso, utilizando-se largamente das terças e sétimas dos acordes, principalmente em tempos fortes, para melhor defini-la. Neste trabalho faremos uma análise simplificada, colocando abaixo das notas que julgamos mais importantes o número referente ao seu intervalo dentro do acorde. Por exemplo: 1- tônica; 3 - terça; 5 - quinta; 7 - sétima.

Seguindo neste mesmo choro, podemos notar que o autor utiliza nos compassos 17, 18 e 19 o que podemos considerar uma abordagem horizontal (A.H.), mas logo a seguir mantém a preferência pelas notas do acorde em tempos fortes, desenho dos baixos descendo cromaticamente, arpejos e alguns cromatismos (Ex.4).

Para este presente artigo só analisaremos a primeira seção deste choro, mas Pixinguinha continua em todas as seções seguindo as mesmas preferências verticais.

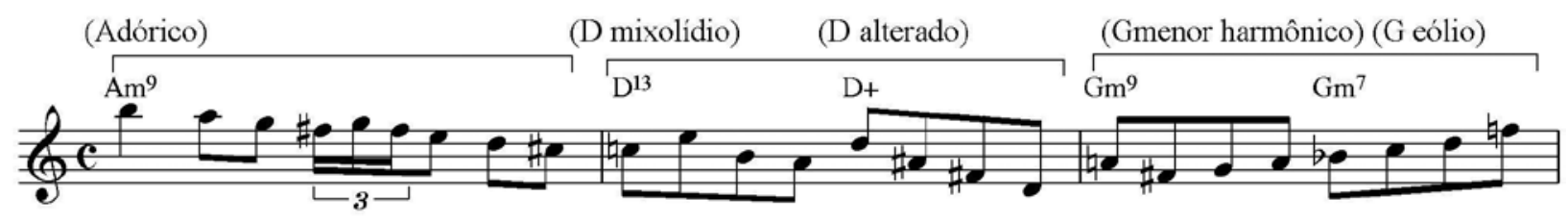

Ex.2 - Exemplo de abordagem vertical (Jamey Aebersold) ${ }^{5}$
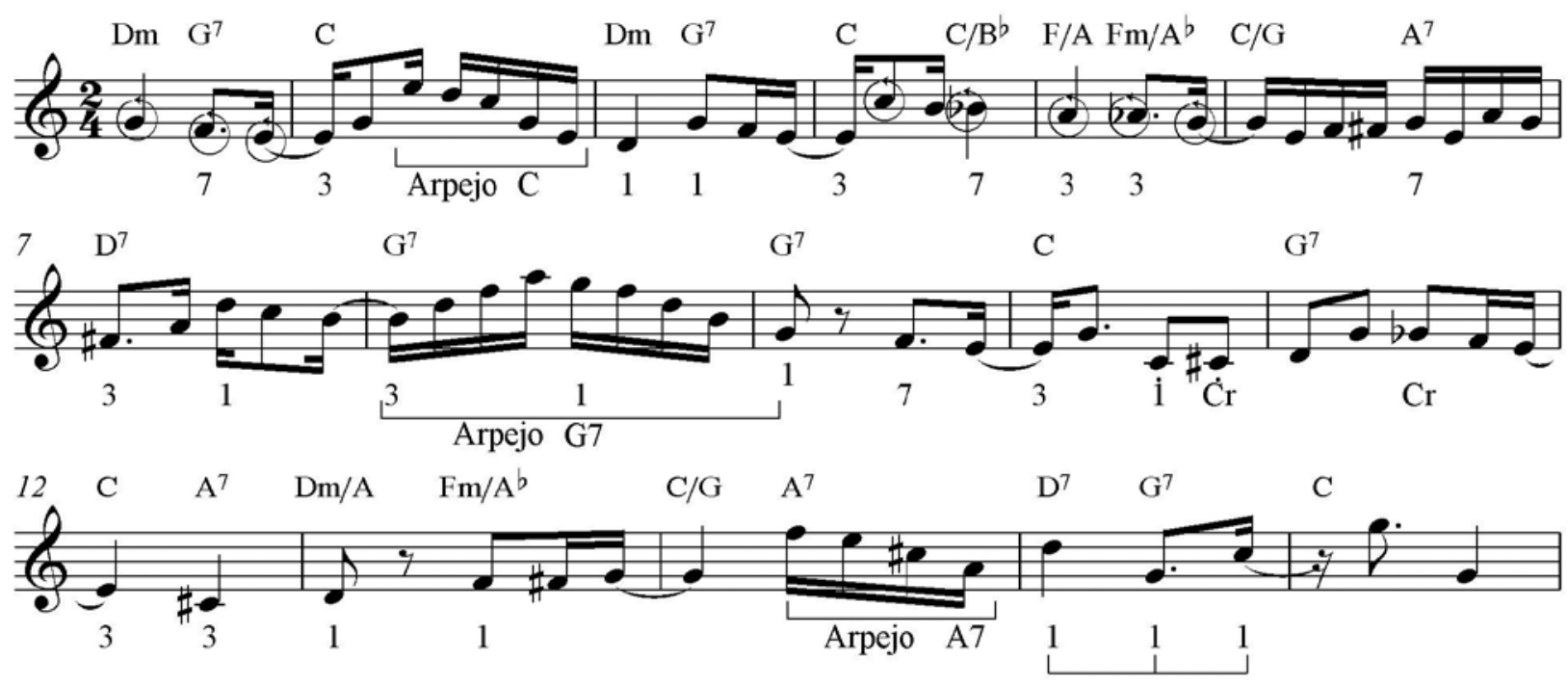

Ex.3 - Contraponto de Pixinguinha em 1 a 0, c.1-16 (100 Anos. BMG, 1997). 
A seguir, o Ex.5 mostra uma tabela separada por seções com o número de vezes que o autor utiliza em tempo forte as fundamentais, terças e sétimas.

\section{4- 0 desenho melódico de K-Ximbinho}

Na música "Velhos Companheiros", choro de sua autoria, notaremos uma maior liberdade de criação e uma clara influência jazzística. CAZES (1998) acredita que K-Ximbinho realizou um casamento perfeito entre o choro e os elementos harmônicos oriundos do jazz, e afirma que "para se ter uma ideia da modernidade do autor, ele foi estudar com Koellreuter, o guru da vanguarda..."

Notamos em seus improvisos um claro pensamento melódico (horizontal), diferente de Pixinguinha que se baseia principalmente no desenho harmônico (vertical).
Podemos notar sobreposições de arpejo, cromatismos, escala de blues, escala bebop (passando pela sétima maior e sétima menor), motivos melódicos característicos da linguagem do jazz, aproximações cromáticas e diatônicas. Há uma preferência pela condução melódica - horizontal sem se preocupar tanto em delinear as harmonias como vimos anteriormente no choro $1 \times 0$, de Pixinguinha. No caso de K-Ximbinho, observaremos principalmente escalas e os motivos melódicos (Ex.6).

Examinamos aqui somente um exemplo de K-Ximbinho, o choro Velhos Companheiros. As análises de outros exemplos de sua improvisação, apresentadas na dissertação de mestrado da autora confirmam as preferências horizontais de K-Ximbinho.
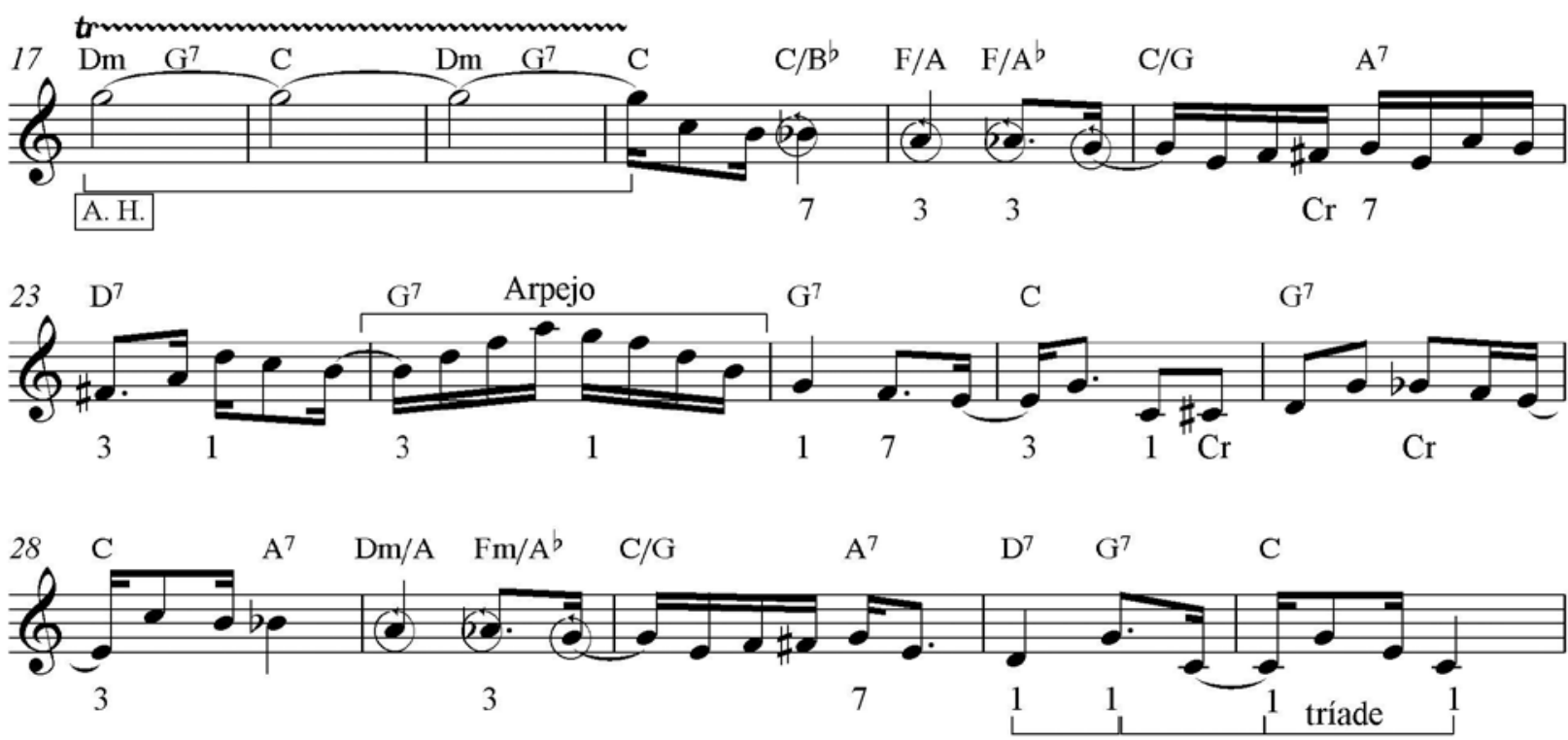

Ex.4 - Contraponto de Pixinguinha em 1 a 0, c.17-32 (100 Anos. BMG, 1997).

\begin{tabular}{|c|c|c|c|}
\hline Seções & Fundamental (1) & Terça (3) & Sétima (7) \\
\hline A1 & 11 & 9 & 4 \\
\hline A2 & 8 & 7 & 4 \\
\hline B & 17 & 4 & 1 \\
\hline A3 & 12 & 3 & 2 \\
\hline C1 & 12 & 3 & 2 \\
\hline C2 & 12 & 3 & 3 \\
\hline A4 & 8 & 6 & 2 \\
\hline
\end{tabular}

Ex.5 - Tabela com número de ocorrências em tempos fortes, de fundamentais, terças e sétimas, utilizadas por Pixinguinha no improviso do choro $1 \times 0$. 
Como características principais, podemos observar que o autor tem uma grande preocupação em apresentar frases longas com vários motivos rítmico-melódicos que são trabalhados criativamente alterando-os de diversas maneiras. A valorização das linhas horizontais está presente de maneira marcante por meio dos desenvolvimentos motívicos, com preferência às escalas ao invés de arpejos.

0 Ex.7 mostra uma tabela com o número de vezes que encontramos fundamentais, terças e sétimas nos tempos fortes em toda a peça.

\section{5 - Conclusão}

$\mathrm{Na}$ análise de Pixinguinha, vemos que o autor utilizase amplamente de fundamentais, terças e sétimas nos tempos fortes, sempre com fundamentais ao final de cada seção. Pixinguinha conduz sua melodia delineando toda a harmonia, isto é, a estrutura harmônica é claramente percebida através do desenho melódico de seu improviso, graças ao uso de vários arpejos e tríades. $\mathrm{Ou}$ tras características encontradas são os cromatismos que servem para se alcançar alguma nota do acorde, dando fluência à linha melódica, uma relação direta com o que chamamos de baixaria no choro. Quando existem acordes invertidos, muitas vezes eles são representados no improviso para que fiquem claros. Encontramos raramente uma abordagem horizontal.

Examinando os improvisos de K-Ximbinho percebese sua preferência pela abordagem horizontal, pois na maioria das vezes há preocupação com o aspecto melódico que se sobrepõe ao harmônico. Observamos nesses exemplos que para K-Ximbinho a sequência de acordes não é determinante em sua forma de improvisar e enfatiza principalmente o aspecto melódico horizontal, não prioriza a plena definição do caminho harmônico, apesar de sempre se adequar a ele. Gostaríamos de ressaltar em algumas ocasiões a presença da abordagem vertical, porém em poucas ocasiões se comparada às características horizontais.

Nosso estudo não pretende afirmar que Pixinguinha só improvisa com base na harmonia sem se preocupar com o desenho melódico, e tampouco que K-Ximbinho não utilizava o estilo contrapontístico, mas sim que notamos que há uma predominância de cada um destes tipos de pensamento no estilo de cada autor.

Sobre esta questão, Nailor "Proveta" de Azevedo, em depoimento realizado em 25/08/2006 observa que "a improvisação no jazz parte da mão direita do piano, em cima das harmonias; já a brasileira nasceu a partir da mão esquerda (baixos), desenhando as inversões".Esta ideia ilustra de maneira simplificada duas tendências básicas dentro da improvisação em geral e que transparece ao analisarmos tanto os improvisos de Pixinguinha, voltados às raizes do choro, quanto os de K-Ximbinho, com forte influência da música norte americana.

Através dessas análises, exemplificamos o conceito da horizontalidade e verticalidade na improvisação e podemos antecipar a existência dessas tendências em outros autores do choro.

Acreditamos que seja importante refletir sobre essas escolhas no momento da improvisação, analisar as características musicais essenciais de cada uma delas, uma vez que isto dará suporte para o estabelecimento de padrões e esquemas que, de maneira didática, lançará novas luzes nos estudos sobre a improvisação no choro brasileiro.

\begin{tabular}{|l|c|}
\hline Fundamental & 12 \\
\hline Terça & 8 \\
\hline Sétima & 6 \\
\hline
\end{tabular}

Ex.7: Tabela com número de ocorrências em tempos fortes, de fundamentais, terças e sétimas, utilizadas por K-Ximbinho no improviso do choro Velhos Companheiros. 

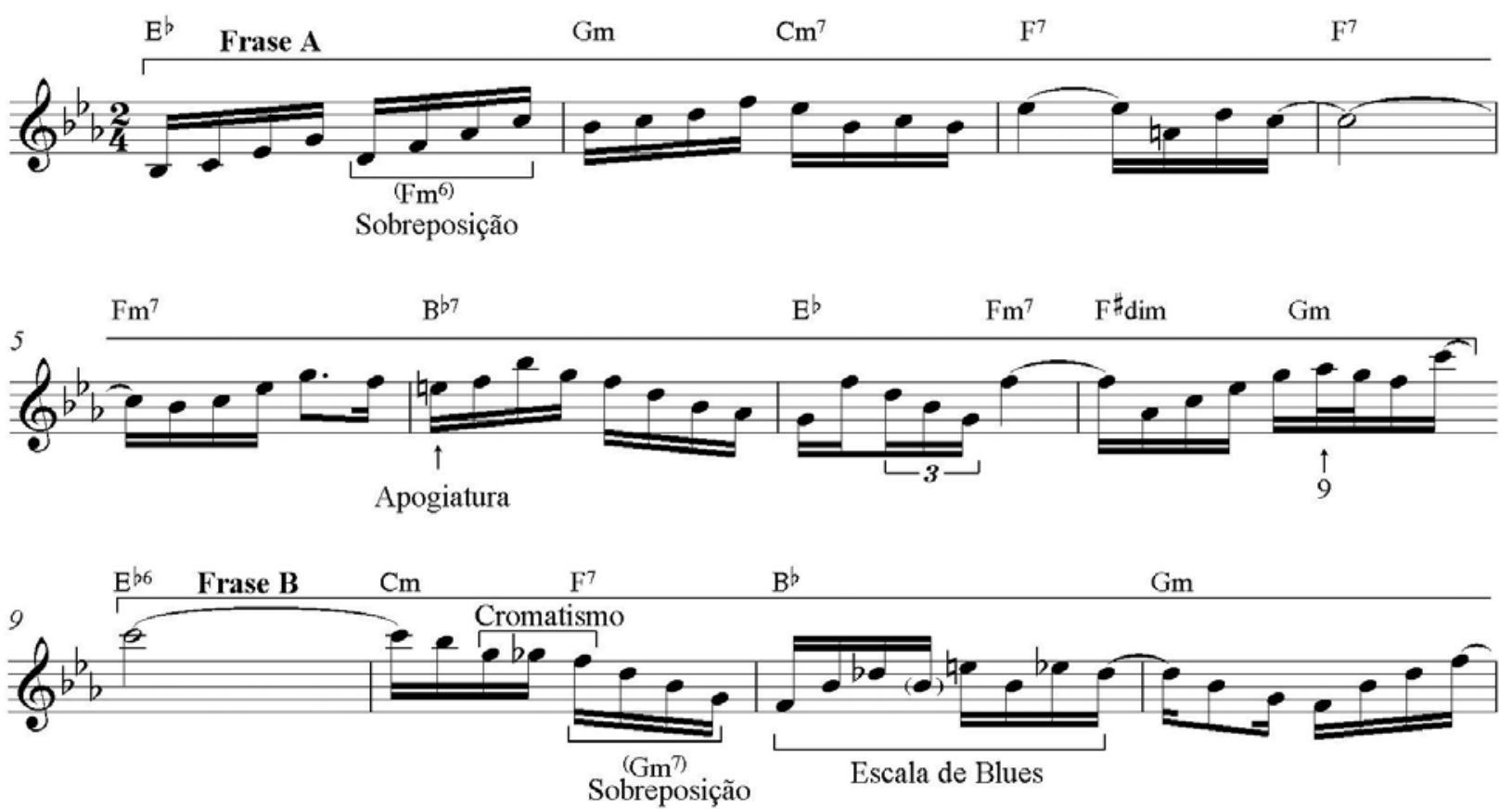

Fm $\mathrm{B}^{\mathrm{b} 7}$ $\mathrm{B}^{\mathrm{b} 7(\$ 5)}$
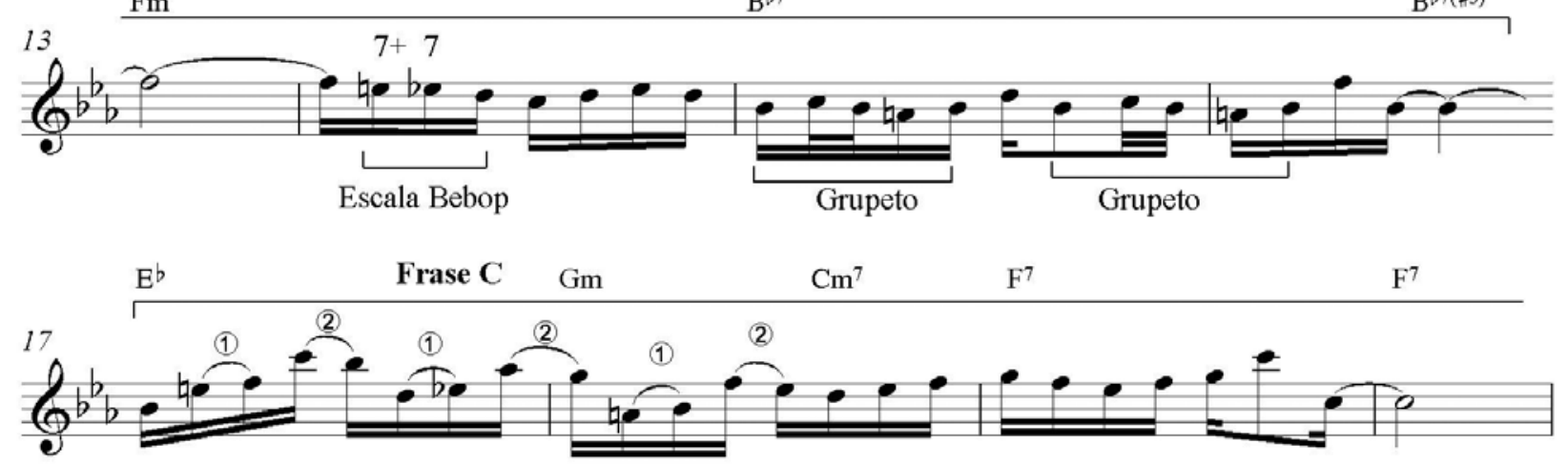

(1) Aproximação cromática inferior

(2) Aproximação diatônica superior
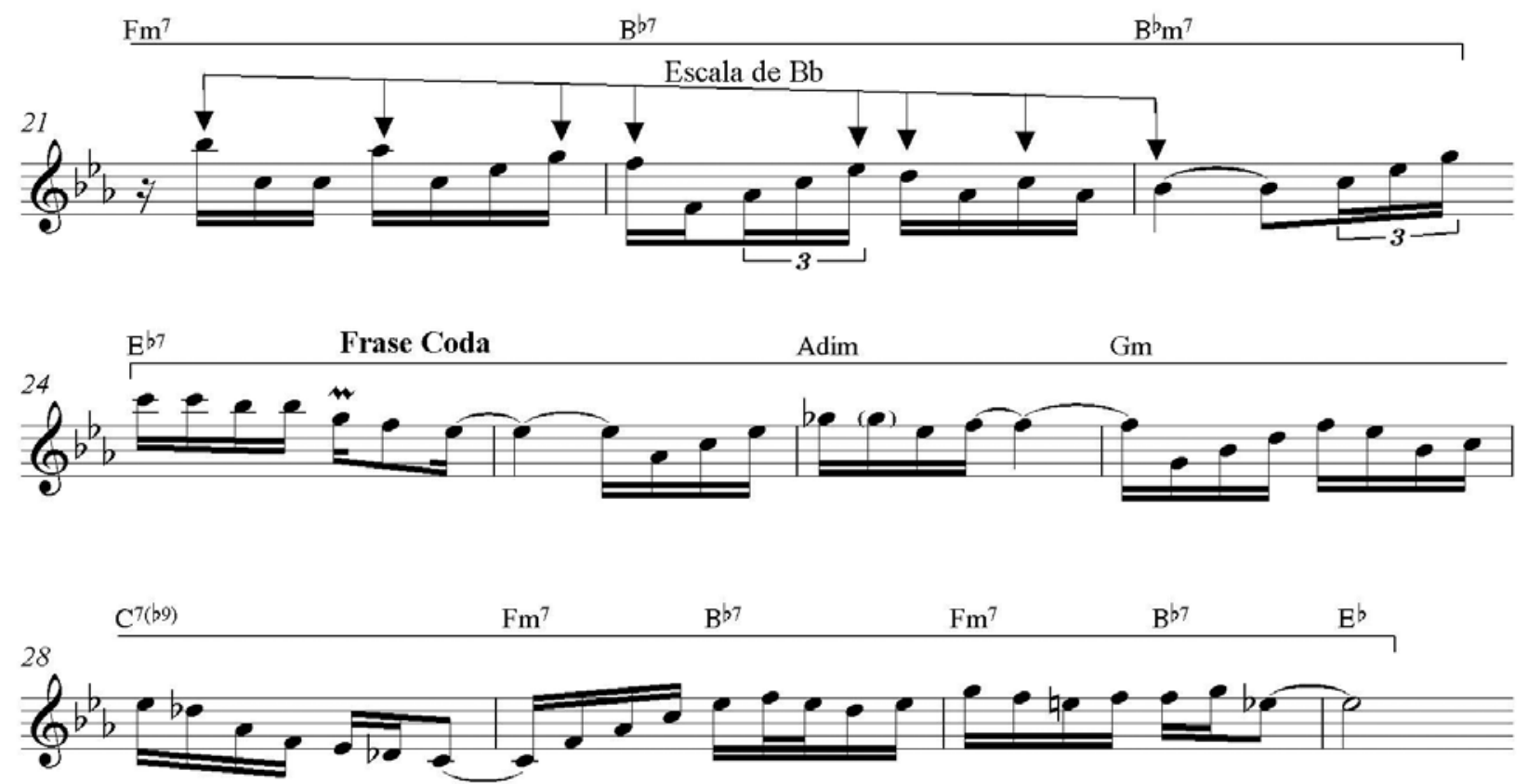

Ex.6 - Improviso de K-Ximbinho em Velhos Companheiros (Saudades de um clarinete. Eldorado,1981). 


\section{Referências}

BAILEY, Derek, Improvisation, its nature and practice in music, England Ashbourne: Da Capo Press, 1993.

BERTON, Cesar Gabriel. Inventividade melódica: Uma outra abordagem das técnicas de análise, composição e improvisação em música popular. Campinas: Unicamp (dissertação), 2005.

CABRAL, Sérgio. Pixinguinha: Vida e obra. Rio de Janeiro: Lumiar Editora, 1997.

NAPOLITANO, Marcos. História e Música - história cultural da música popular. Belo Horizonte: Autêntica, 2002.

RUSSELL, George - Lidian Cromatic Concept of Tonal Organization - Concept Publish Company, 40 Shepard Street; Cambridge, MA 02138, 2001.

VALENTE, Paula Veneziano. Horizontalidade e Verticalidade: dois modelos de improvisação no choro brasileiro. São Paulo: Eca/Usp, (Dissertação), 2009.

\section{Referências sonoras}

K-XIMBINHO. Saudades de um clarinete. K-Ximbinho: composição, regência e clarinete. São Paulo: Gravadora Eldorado,1981 (CD digital estéreo).

PIXINGUINHA: 100 Anos. BMG, 1997.

\section{Leitura recomendada}

CÂMARA, Leide. K-ximbinho. In: Dicionário da Música do Rio Grande do Norte. Natal:

Acervo da Música Potiguar, 2001.

FABRIS, Bernardo V. Catita de k-ximbinho e a interpretação do saxofonista Zé Bodega: aspectos híbridos entre o choro e o jazz. UFMG/Música: (Dissertação), 2006.

FRANCESCHI, Humberto Moraes. A Casa Edison e seu tempo. Rio de Janeiro: Sarapui, 2002.

MAGALHÃES, Alexandre Caldi. Contracantos de Pixinguinha: contribuições históricas e analíticas para a caracterização do estilo. Rio de Janeiro: Universidade do Rio de Janeiro, Música Brasileira, (Dissertação), 2001.

PIEDADE, Acácio Tadeu de Camargo. Jazz, Música Brasileira e fricção de musicalidades. Revista Opus. 11, 2005, p.197-207. Análise musical e música popular brasileira: em busca de tópicas. II Jornada de Pesquisa do Centro de Artes, Florianópolis, 2006. Anais, Florianópolis: UDESC, 2006.

Expressão e sentido na música brasileira: retórica e análise musical. III Simpósio de Pesquisa em Música - SIMPEMUS 3, Curitiba, 2006. Anais..., Curitiba: Editora do DeArtes, 2006, p.63-68.

PINTO, Alexandre Gonçalves. O choro. Rio de Janeiro, Edição FUNARTE, 1978.

SCHULLER, Gunther. Early Jazz: It's roots and musical development. New York: Oxford University Press, 1986.

SILVA, Marília Barboza da \& OLIVEIRA FILHO, Arthur L. de. Pixinguinha - filho de Ogum Bexiguento. Rio de Janeiro, Gryphus, 1998.

\section{Notas}

10 material encontra-se nas referências do final do artigo.

2 A improvisação idiomática se preocupa principalmente com a expressão de um idioma - como o jazz, a música flamenca ou barroca - e tem sua identidade e motivação originada desses idiomas. A improvisação não idiomática tem outra preocupação e é mais encontrada no que chamamos de livre improvisação, que não está atrelada a nenhuma identidade idiomática (tradução da autora).

3 A escala blues é uma escala de seis notas. Quando comparada com uma escala maior, a escala blues é assim construída sobre os graus da escala de sete notas: $1, b 3,4, b 5,5, b 7$.

4 Exemplo citado em BERTON (2005, p.72).

5 Exemplo citado em BERTON (2005, p.73).

6 No contexto do choro, contraponto ou contracanto é uma melodia de acompanhamento que dialoga com a melodia principal sendo uma das principais caracteristicas desta linguagem.

7 Como exemplo, citamos o grupo Choro Carioca (1910 a 1915) em que Irineu de Almeida, professor de Pixinguinha, já fazia estes contracantos ao oficleide.

8 A análise integral deste choro encontra-se na dissertação de mestrado da autora.

9 VALENTE, Paula Veneziano. Horizontalidade e Verticalidade: dois modelos de improvisação no choro brasileiro. São Paulo: Eca/Usp, (Dissertação), 2009 .

Paula Veneziano Valente é Graduada em Composição e Regência pela UNESP (Universidade Estadual Paulista), Mestre pela USP, saxofonista e flautista da Orquestra Jazz Sinfônica do Estado de São Paulo desde 1990. Na área didática atua como professora de saxofone e coordenadora de sopros populares na EMESP - Tom Jobim (antiga Universidade Livre de Música-ULM). 